\title{
Postreactivation Glucocorticoids Impair Recall of Established Fear Memory
}

\author{
Wen-Hui Cai, ${ }^{1,2 \star}$ Jacqueline Blundell, ${ }^{3 *}$ Jie Han, ${ }^{1}$ Robert W. Greene, ${ }^{1,2}$ and Craig M. Powell 1,3 \\ ${ }^{1}$ Psychiatry, The University of Texas Southwestern Medical Center, Dallas, Texas 75390-9070, ${ }^{2}$ Psychiatry, The Veterans Affairs Hospital, Dallas, Texas \\ 75216, and ${ }^{3}$ Neurology, The University of Texas Southwestern Medical Center, Dallas, Texas 75390-8813
}

Pavlovian fear conditioning provides one of the best rodent models of acquired anxiety disorders, including posttraumatic stress disorder. Injection of a variety of drugs after training in fear-conditioning paradigms can impair consolidation of fear memories. Indeed, early clinical trials suggest that immediate administration of such drugs after a traumatic event may decrease the risk of developing posttraumatic stress disorder in humans (Pitman et al., 2002; Vaiva et al., 2003). The use of such a treatment is limited by the difficulty of treating every patient at risk and by the difficulty in predicting which patients will experience chronic adverse consequences. Recent clinical trials suggest that administration of glucocorticoids may have a beneficial effect on established posttraumatic stress disorder (Aerni et al., 2004) and specific phobia (Soravia et al., 2006). Conversely, glucocorticoid administration after training is known to enhance memory consolidation (McGaugh and Roozendaal, 2002; Roozendaal, 2002). From a clinical perspective, enhancement of a fear memory or a reactivated fear memory would not be desirable. We report here that when glucocorticoids are administered immediately after reactivation of a contextual fear memory, subsequent recall is significantly diminished. Additional experiments support the interpretation that glucocorticoids not only decrease fear memory retrieval but, in addition, augment consolidation of fear memory extinction rather than decreasing reconsolidation. These findings provide a rodent model for a potential treatment of established acquired anxiety disorders in humans, as suggested by others (Aerni et al., 2004; Schelling et al., 2004), based on a mechanism of enhanced extinction.

Key words: learning; memory; reconsolidation; consolidation; fear conditioning; recall; extinction; glucocorticoid

\section{Introduction}

Newly formed fear memories undergo a process of consolidation at the cellular level immediately after training (Nader et al., 2000a; Abel and Lattal, 2001; Dudai, 2004). This consolidation process is required for long-term maintenance of the memory trace. Protein synthesis inhibitors and other pharmacologic agents interfere with memory consolidation (Flexner et al., 1965; Davis and Squire, 1984; Bourtchouladze et al., 1998; McGaugh, 2000). Growing evidence suggests that fear memories have a selective sensitivity to pharmacologic interventions, including protein synthesis inhibition, after reactivation, in a manner that can negatively affect subsequent memory retrieval (Schneider and Sherman, 1968; Przybyslawski and Sara, 1997; Nader et al., 2000a; Sara, 2000; Pedreira and Maldonado, 2003; Suzuki et al., 2004). Of particular note, established memories may also be affected during reactivation through extinction, another process amena-

Received 0ct. 19, 2005; revised Aug. 7, 2006; accepted Aug. 7, 2006.

This work was supported by National Institute of Mental Health Grant MH065975, Conte Center Grant MH6045, the National Alliance for Research on Schizophrenia and Depression, and the Department of Veterans Affairs. R.W.G. C.M.P., W.-H.C., and J.B. conceived and designed the experiments; W.-H.C., J.H., and J.B. performed the experiments with input from C.M.P.; W.-H.C., J.H., J.B., and C.M.P. performed statistical analysis; and C.M.P. wrote this paper with input from W.-H.C., J.B., and R.W.G. We thank Dr. Eric J. Nestler for helpful comments.

${ }^{*} W$.-H.C. and J.B. contributed equally to this work.

Correspondence should be addressed to Robert W. Greene, 5323 Harry Hines Boulevard, Dallas, TX 75390-9070. E-mail: robertw.greene@utsouthwestern.edu.

D0I:10.1523/JNEUROSCI.2397-06.2006

Copyright $\odot 2006$ Society for Neuroscience $\quad$ 0270-6474/06/269560-07\$15.00/0 ble to pharmacologic manipulation (Bouton, 1993; Myers and Davis, 2002).

Although the process of consolidation and processes occurring after reactivation require overlapping molecular pathways, a recent study suggests there are molecularly distinct processes involved in each (Lee et al., 2004). Likewise, extinction consolidation appears to be distinct in many respects compared with initial fear memory consolidation (Bouton, 1993; Myers and Davis, 2002). Pharmacologic modulation of the reactivation process to alter subsequent recall has not been fully characterized despite its potential as a feasible therapeutic target. Glucocorticoid administration in humans has been shown recently to be a relevant pharmacologic treatment of established disorders of emotional memories such as posttraumatic stress disorder (PTSD) and phobias (Aerni et al., 2004; Soravia et al., 2006). These effects of glucocorticoids appear to involve both inhibition of memory retrieval and facilitation of extinction (Aerni et al., 2004; Soravia et al., 2006). Here, we demonstrate that the endogenous stress hormone, corticosterone (Cort), can reduce subsequent recall of an established contextual fear memory in mice after a single-trial reactivation, and that this effect is dependent on both reactivation of the memory and timing of corticosterone administration relative to memory reactivation. In addition, corticosterone can decrease single-trial fear memory retrieval without affecting underlying memory stability, whereas repeated retrieval in the presence of glucocorticoids can augment extinction of the contextual fear memory. These studies implicate multiple overlapping 

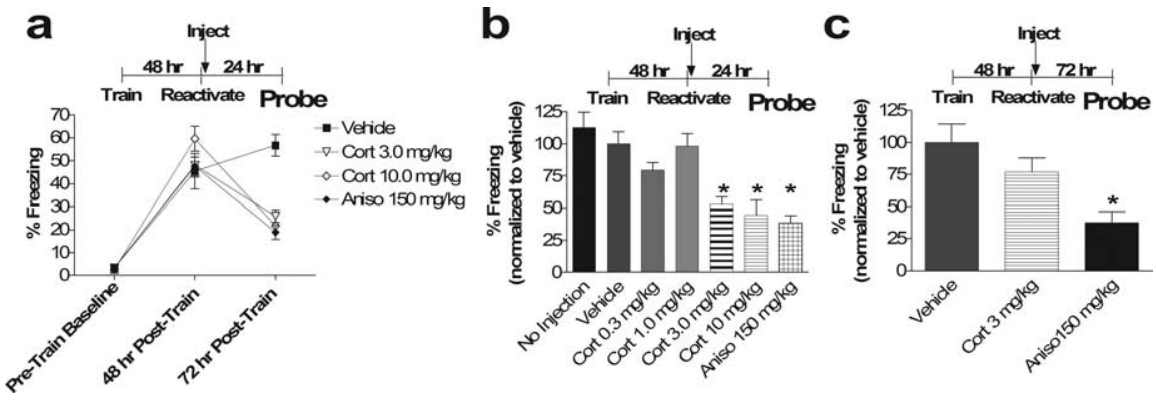

Figure 1. Postretrieval corticosterone transiently impairs subsequent recall of contextual fear conditioning. $\boldsymbol{a}$, Percentage of time spent freezing in the training context before training in fear conditioning (Baseline), during subsequent reactivation $48 \mathrm{~h}$ hence ( $48 \mathrm{~h}$ from Train), and $24 \mathrm{~h}$ after reactivation ( $72 \mathrm{~h}$ from Train). Reactivation was followed by injection of vehicle or corticosterone at the indicated dose (one-way ANOVA for $72 \mathrm{~h}$ time point, $p<0.001, F_{(3,28)}=10.06$; post hoc Tukey's test, $p<$ 0.01 for Cort $3 \mathrm{mg} / \mathrm{kg}$ vs vehicle, $p<0.001$, for Cort $10 \mathrm{mg} / \mathrm{kg}$ vs vehicle, $p=0.65$, for Cort $3 \mathrm{mg} / \mathrm{kg}$ vs Aniso, $p=0.96$, for Cort $10 \mathrm{mg} / \mathrm{kg}$ vs Aniso, $p<0.001$, for Aniso vs vehicle, $p=0.90$, for Cort $3 \mathrm{mg} / \mathrm{kg}$ vs Cort $10 \mathrm{mg} / \mathrm{kg}$ ). $\boldsymbol{b}$, Subsequent contextual memory recall is blocked by higher doses of corticosterone, and this effect resembles that of anisomycin. A dose-response curve for corticosterone administered immediately after memory reactivation is shown. Bars represent percentage of freezing $72 \mathrm{~h}$ after training (24 h after memory reactivation) (one-way ANOVA, $p<0.0001, F_{(6,49)}=10.86$; post hoc Tukey's test, vehicle vs no injection, $p=0.95$, vs Cort $0.3 \mathrm{mg} / \mathrm{kg}, p=0.11$, vs Cort $1 \mathrm{mg} / \mathrm{kg}, p=0.99$, vs Cort $3 \mathrm{mg} / \mathrm{kg}, p<0.05$, vs Cort $10 \mathrm{mg} / \mathrm{kg}, p<0.01$, vs Aniso, $p<0.001$ ). No Injection was significantly different from Aniso, Cort $3 \mathrm{mg} / \mathrm{kg}$, and Cort $10 \mathrm{mg} / \mathrm{kg}$ ( $p<0.001$ for all) and not different from Vehicle, Cort $0.3 \mathrm{mg} / \mathrm{kg}$, or Cort $1 \mathrm{mg} / \mathrm{kg}$ ( $p=0.95,0.15$, and 0.92 , respectively). Cort $3 \mathrm{mg} / \mathrm{kg}$ differed from vehicle, Cort $1 \mathrm{mg} / \mathrm{kg}$, and No Injection ( $p<0.05,0.05$, and 0.01, respectively) but did not differ from Cort $0.3 \mathrm{mg} / \mathrm{kg}$ or Aniso ( $p=0.39$ and 0.92 , respectively). Similarly, Cort $10 \mathrm{mg} / \mathrm{kg}$ differed from vehicle, Cort $1 \mathrm{mg} / \mathrm{kg}$, and No Injection ( $p<0.01,0.01$, and 0.001 , respectively) but did not differ from Cort $0.3 \mathrm{mg} / \mathrm{kg}$ or Aniso ( $p=0.11$ and 0.99 , respectively). ${ }^{*} p<0.05$ on post hoc Tukey's test versus vehicle and No Injection. $\boldsymbol{c}$, Effect of corticosterone on subsequent memory recall is transient. Error bars represent freezing $120 \mathrm{~h}(5 \mathrm{~d})$ after training ( $72 \mathrm{~h}$ after memory reactivation). When tested $72 \mathrm{~h}$ after reactivation, the anisomycin effect on subsequent recall remained, whereas that of corticosterone is no longer present (ANOVA main effect of drug, $p<0.01$, $F_{(2,21)}=7.72 ;$ post hoc Tukey's test vehicle vs Aniso, ${ }^{*} p<0.01$, vehicle vs Cort, $p=0.34$; Aniso vs Cort, $p=0.058$ ). Although $\boldsymbol{b}$ and $c$ were necessarily performed in separate experiments in different groups on different days and thus normalized to separate control groups, a Student's t test comparison between Cort $3 \mathrm{mg} / \mathrm{kg}$ at $24 \mathrm{~h}$ from $\boldsymbol{b}$ and Cort $3 \mathrm{mg} / \mathrm{kg}$ at $72 \mathrm{~h}$ from crevealed a $p=$ 0.068 , whereas a similar comparison of Aniso $150 \mathrm{mg} / \mathrm{kg}$ at $24 \mathrm{~h}$ from $\boldsymbol{b}$ and Aniso $150 \mathrm{mg} / \mathrm{kg}$ from c revealed a $p=0.94 . n=8$ in all groups. Error bars represent SEM in all figures.

mechanisms of action for glucocorticoids in the treatment of acquired anxiety disorders.

\section{Materials and Methods}

Behavior. Fear conditioning was performed essentially as described previously (Powell et al., 2004). Briefly, 8-week-old male C57BL/6 mice from Jackson Laboratories (Bar Harbor, ME) were placed in a Plexiglas shock box with clear front and rear walls (MedAssociates, Georgia, VT) for $2 \mathrm{~min}$, and then a $30 \mathrm{~s}, 90 \mathrm{~dB}$ tone coterminating in a $2 \mathrm{~s}, 0.5 \mathrm{~mA}$ footshock was delivered twice with a $1 \mathrm{~min}$ interstimulus interval. Mice remained in the context for $2 \mathrm{~min}$ before returning to their home cage. After different intervals, as described here, freezing behavior in the training context was monitored every $10 \mathrm{~s}$ for $5 \mathrm{~min}$ by an observer blind to the experimental manipulation to measure contextual fear conditioning. Student's $t$ test was used for two-group comparisons, whereas one-way ANOVA with post hoc Tukey's tests were used in experiments with multiple groups. Significance was taken as $p<0.05$. Extinction training involved daily $5 \mathrm{~min}$ exposures to the training context.

Because glucocorticoids blocked expression of fear memory retrieval, we examined the locomotor activity, anxiety state, and nociception effects of glucocorticoids to ensure that we were not simply affecting behavioral expression of the memory. Open-field locomotor activity was performed for $10 \mathrm{~min}$ in a $48 \times 48 \times 48 \mathrm{~cm}$ white plastic arena placed on the floor with fluorescent, ceiling-mounted lighting and analyzed using automated video tracking software from Noldus (Ethovision 2.3.19; Noldus Information Technology, Sterling, VA) to track velocity, distance moved, and time spent in the "center" zone, defined as a $15 \times 15 \mathrm{~cm}$ square in the center of the arena. Elevated plus maze behavior was tested by placing mice in the center of a black Plexiglas elevated plus maze with white floors (each arm was $33 \mathrm{~cm}$ long and $5 \mathrm{~cm}$ wide with $25 \mathrm{~cm}$ high walls on closed arms) in a dimly lit room for $5 \mathrm{~min}$ as described previously (Powell et al., 2004). Each session was videotaped for later analysis by an observer blind to the genotype of the mice. Time spent in the open and closed arms, number of open and closed arm entries, time spent in the middle, and number of explorations of the open arm (defined as placing head and two limbs into open arm without full entry) was calculated. The apparatus was wiped with $70 \%$ ethanol and air-dried between mice. Accelerating rotarod behavior was performed as described previously (Powell et al., 2004) Briefly, an accelerating rotarod designed for mice (IITC Life Science, Woodland Hills, CA) was used. The rotarod was activated after placing mice on the motionless rod. The rod accelerated from $0-45$ revolutions per $\min$ in $60 \mathrm{~s}$. The time to fall off the rod or to turn one full revolution was measured. Five trials were performed 20-30 min apart in succession. Data were analyzed with two-way ANOVA.

Footshock sensitivity was performed by placing mice in the contextual conditioning chamber for a 2 min habituation period followed by a $2 \mathrm{~s}$ footshock every $30 \mathrm{~s}$. The shock amplitude started at $0.05 \mathrm{~mA}$ and was increased by 0.05 $\mathrm{mA}$ with successive stimuli. The stimulus amplitudes required to elicit behavioral responses of flinching, jumping, and vocalizing were recorded.

Drug preparation/administration. A corticosterone (Sigma, St. Louis, MO) and anisomycin (Aniso) stock solution was prepared for each dose in normal saline with $5 \%$ ethanol. Stock solutions of corticosterone and anisomycin were kept at $4^{\circ} \mathrm{C}$ in light-tight boxes and were made the day before the experiment or the morning of the experiment. Mice were weighed on the morning of the experiment and injected intraperitoneally with volumes ranging from 0.3 to $0.5 \mathrm{ml}$. Doses used were corticosterone $0.1,1,3$, and $10 \mathrm{mg} / \mathrm{kg}$ based on pilot data. Three and $10 \mathrm{mg} / \mathrm{kg}$ corticosterone were used in follow-up experiments because of their effects in our dose-response experiment (see Fig. 1). Anisomycin, $150 \mathrm{mg} / \mathrm{kg}$, was chosen as a dose at the high range of anisomycin reconsolidation effects in mice (Lattal and Abel, 2004).

Corticosterone measurement. Corticosterone measurements were performed following those of de Quervain et al. (1998). C57BL/6 mice at 8 weeks of age were injected intraperitoneally with vehicle or corticosterone (Sigma) at $0.3,1.0,3.0$, or $10 \mathrm{mg} / \mathrm{kg}$ at time 0 . Thirty minutes after injection, the mice were killed, and the trunk blood was collected in heparinized tubes and stored on ice. Plasma was isolated via centrifugation at $5000 \mathrm{rpm}$ for $10 \mathrm{~min}$ and stored on ice until freezing at $-20^{\circ} \mathrm{C}$ before corticosterone measurement ( $n=8$ /group). Corticosterone measurements were performed on plasma using Corticosterone Radioimmunoassay kit (B3-163; Endocrine Sciences, Tarzana, CA).

\section{Results}

We trained male C57BL/6 mice in a classical fear conditioning paradigm in which a novel environment is paired with footshock. Forty-eight hours later, re-exposure to the training environment elicited significant fear responses indicating reactivation of a learned association between this environment and the aversive footshock stimulus (Fig. $1 a, 48 \mathrm{~h}$ ). Two to $5 \mathrm{~min}$ after this reactivation, mice were injected with various doses of corticosterone $(0.3,1.0,3.0$, and $10.0 \mathrm{mg} / \mathrm{kg})$, anisomycin $(150 \mathrm{mg} / \mathrm{kg})$, or vehicle and tested $24 \mathrm{~h}$ later for contextual fear memory. Mice injected with 3.0 and $10.0 \mathrm{mg} / \mathrm{kg}$ corticosterone after memory reactivation showed significantly decreased contextual fear memory $24 \mathrm{~h}$ later ( $p<0.01$ and 0.001 , respectively) that was indistinguishable in magnitude from the effect of anisomycin 


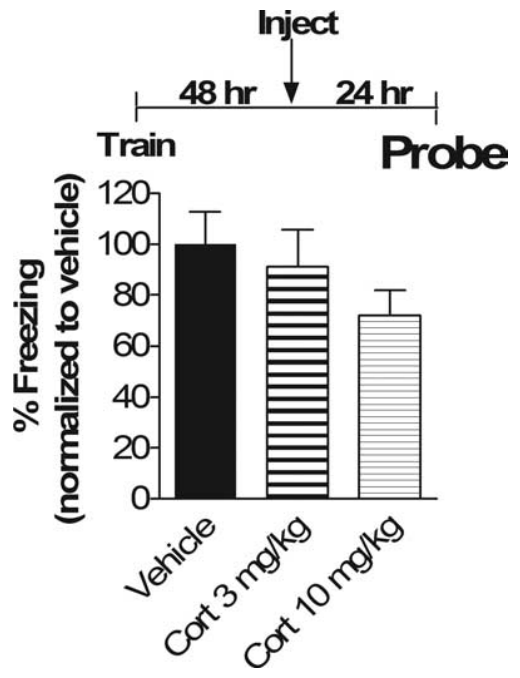

Figure 2. Reactivation of the memory is necessary for the corticosterone effect on subsequent recall. Mean percentage time spent freezing in contextual memory test $24 \mathrm{~h}$ after injection of corticosterone or vehicle is shown ( $72 \mathrm{~h}$ from Train). ANOVA revealed no main effect of $\operatorname{drug}\left(p=0.33 ; F_{(2,33)}=1.16\right)$. Because there was no main effect, post hoc Tukey's test revealed no significant differences between vehicle versus Cort $3 \mathrm{mg} / \mathrm{kg}$ or Cort $10 \mathrm{mg} / \mathrm{kg}$ ( $p=$ 0.88 and 0.31 , respectively) and no differences between Cort $3 \mathrm{mg} / \mathrm{kg}$ versus Cort $10 \mathrm{mg} / \mathrm{kg}$ $(p=0.57) . n=12$ in all groups.

( $p=0.65$ and 0.96 for Cort $3 \mathrm{mg} / \mathrm{kg}$ and $10 \mathrm{mg} / \mathrm{kg}$, respectively) (Fig. 1a). Mice injected with vehicle and mice injected with lower doses of corticosterone after memory reactivation exhibited no significant change in subsequent fear memory ( $p=0.11$ for Cort $0.3 \mathrm{mg} / \mathrm{kg}$ and $p=0.91$ for Cort $1 \mathrm{mg} / \mathrm{kg}$ vs vehicle) (Fig. 1b). Thus, corticosteroids impair subsequent recall of a reactivated fear memory trace. The effect of glucocorticoid administration after reactivation on subsequent recall may be attributable to decreasing a reconsolidation process or augmentation of extinction.

To distinguish between a reconsolidation effect and an extinction effect, we next examined the duration of the glucocorticoid effect on subsequent recall to determine whether there was a deficit in the underlying stability of the memory trace. We tested the effects of glucocorticoid administration $72 \mathrm{~h}$ after the reactivation and found no significant effect on subsequent memory recall $(p=0.34)$ (Fig. 1c). However, the anisomycin effect on subsequent memory recall persisted $(p<0.01)$ (Fig. $1 c)$. This finding suggests that glucocorticoids impair subsequent recall of a memory trace only transiently when paired with reactivation, and the duration of this effect differs from that of anisomycin. The spontaneous recovery of subsequent memory recall and the transient nature of the effect compared with anisomycin suggest an effect on extinction.

If glucocorticoids selectively impair subsequent recall of only reactivated memory traces, then administration of corticosterone $48 \mathrm{~h}$ after training in the absence of fear memory reactivation should not affect subsequent memory. When mice were trained in contextual fear conditioning and injected $48 \mathrm{~h}$ later with 3.0 $\mathrm{mg} / \mathrm{kg}$ or $10.0 \mathrm{mg} / \mathrm{kg}$ corticosterone in the absence of fear memory reactivation, no effect was observed on subsequent memory measured $24 \mathrm{~h}$ after injection ( $p=0.88$ and 0.31 , respectively) (Fig. 2). Thus, the effect of glucocorticoids on subsequent fear memory recall is dependent on reactivation of the memory trace and is not simply a result of prolonged effects of glucocorticoids alone.

Extinction of a fear memory can be reversed by exposure to a a

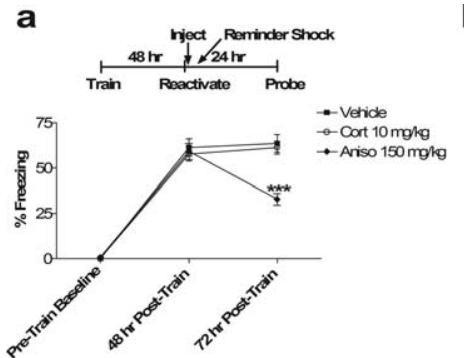

b
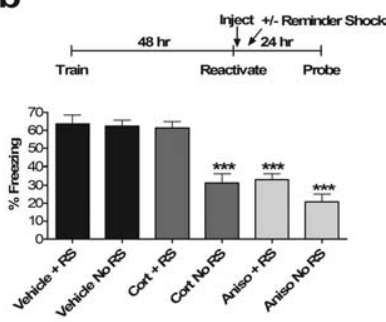

Figure 3. $\quad \boldsymbol{a}$, Reminder shock rescues post-reactivation glucocorticoid effect on subsequent memory and spares that of anisomycin. ANOVA at the $72 \mathrm{~h}$ time point after reminder shock reveals a main effect of drug $\left(p<0.00001 ; F_{(2,33)}=19.52\right)$. Post hoc Tukey's test shows significant differences between vehicle and Aniso and between Cort and Aniso ( $p<0.001$ for both). There was no significant difference between vehicle and Cort with reminder shock ( $p=$ $0.91)$. ${ }^{* * *} p<0.001$ versus corresponding vehicle control. No significant differences were observed in pretrain baseline or $48 \mathrm{~h}$ posttrain groups ( $n=12$ in all groups). $\boldsymbol{b}$, Comparison of reminder shock ( $+R S$ ) versus no-reminder shock (no RS) groups on the final day of testing for each drug. ${ }^{* * *} p<0.001$ versus corresponding vehicle control. Two-way ANOVA: main effect of drug, $F_{(2,66)}=37.25, p<0.001$; main effect of RS/no RS, $F_{(1,66)}=13.76, p<0.001$; interaction, $F_{(2,66)}=5.42, p<0.01$. Post hoc Tukey's test indicated significant differences between Cort/no RS, Aniso/RS, and Aniso/no RS versus all other groups and vice versa; $p<0.001$ for all post hoc differences. Nonsignificant $p$ values were 0.36 for Cort/no RS versus Aniso/no RS, 0.47 for Aniso/RS versus Aniso/no RS, 0.99 for Aniso/RS versus Cort/no RS, 0.99 for Cort/RS versus Vehicle/no RS, and 0.99 for Vehicle/RS versus Vehicle/no RS ( $n=12$ in all groups). No significant differences were observed in pretrain baseline or $48 \mathrm{~h}$ posttrain groups.

"reminder shock" that is below the threshold for de novo fear conditioning, whereas reconsolidation effects theoretically cannot. To further distinguish between effects on extinction versus reconsolidation, we repeated our initial experiments giving vehicle, corticosterone, and anisomycin after reactivation. In half of the animals, however, we interposed a subthreshold $(0.3 \mathrm{~mA} \times 1)$ reminder shock $4 \mathrm{~h}$ after memory reactivation. The reminder shock resulted in no significant contextual fear conditioning in naive mice (data not shown). As expected for an effect on extinction, the effect of corticosterone was completely reversed by interposing a reminder shock $4 \mathrm{~h}$ after reactivation ( $p=0.91$ vs Vehicle) (Fig. 3). The anisomycin group was unaffected by the reminder shock as expected for its effect on reconsolidation ( $p=$ 0.47 for Aniso with reminder shock vs Aniso without reminder shock). These data argue for an effect of corticosterone on extinction learning rather than reconsolidation.

Administration of corticosterone $30 \mathrm{~min}$ prior to contextual fear memory reactivation impaired retrieval of the fear memory during reactivation $(p<0.01)$ (Fig. $4 a$ ). Measurement of corticosterone levels $30 \mathrm{~min}$ after intraperitoneal injection indicate that a $3.0 \mathrm{mg} / \mathrm{kg}$ injection produced corticosterone levels well within the range observed with physiologic stressors in mice (supplemental Table 1, available at www.jneurosci.org as supplemental material) (Pawlak et al., 2003; Hebda-Bauer et al., 2004).

Administration of glucocorticoids prior to memory reactivation, which impairs acute retrieval (Fig. 4a), does not significantly affect subsequent recall in the absence of glucocorticoids (Fig. $4 b$ ). Mice were trained in the fear conditioning paradigm on day 1 and administered $3.0 \mathrm{mg} / \mathrm{kg}$ or $10 \mathrm{mg} / \mathrm{kg}$ corticosterone 30 min before memory reactivation $48 \mathrm{~h}$ later, which led to a significantly impaired recall response $(p<0.01)$ (Fig. $4 a)$. On repeat fear memory testing in the absence of drug $24 \mathrm{~h}$ after blocking retrieval with corticosterone ( $72 \mathrm{~h}$ after training), contextdependent fear conditioning was not statistically different from controls ( $p=0.36$ for $3 \mathrm{mg} / \mathrm{kg}$ and 0.33 for $10 \mathrm{mg} / \mathrm{kg}$ ) (Fig. $4 b$ ), although a trend toward a decrease was noted. Because Figure $4 a$ 

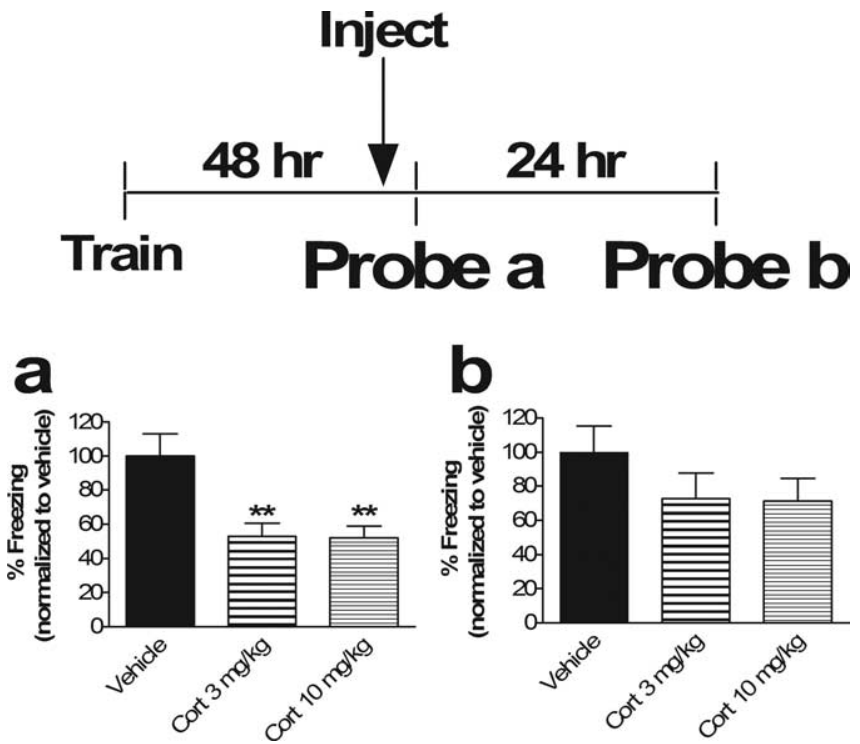

Figure 4. Corticosterone impairs acute retrieval of contextual fear memory without affecting the stability of the underlying memory trace. $a$, Injection of corticosterone $30 \mathrm{~min}$ before memory test impairs retrieval. Results of "Probe a" (contextual memory test performed $48 \mathrm{~h}$ after training; percentage freezing in context 30 min after corticosterone injection) are shown. ANOVA revealed a main effect of $\operatorname{drug}\left(p<0.01, F_{(2,33)}=7.49\right)$. Post hoc Tukey's test revealed significant differences between vehicle versus Cort $3 \mathrm{mg} / \mathrm{kg}(p<0.01)$ and versus Cort 10 $\mathrm{mg} / \mathrm{kg}(p<0.01)$. No significant difference between Cort $3 \mathrm{mg} / \mathrm{kg}$ and Cort $10 \mathrm{mg} / \mathrm{kg}$ was observed $(p=0.99)$. ${ }^{* *} p<0.01 ; n=12$ in all groups. $\boldsymbol{b}$, Impairment of memory retrieval by corticosterone had no significant effect on subsequent memory. Results of "Probe b" (contextual memory test performed $72 \mathrm{~h}$ after training or $24 \mathrm{~h}$ after Probe a; percentage freezing in context $24 \mathrm{~h})$ are shown. ANOVA revealed no main effect of $\operatorname{drug}\left(p=0.28 ; F_{(2,33)}=1.33\right)$. Because there was no main effect, post hoc Tukey's test revealed no significant differences between vehicle versus Cort $3 \mathrm{mg} / \mathrm{kg}$ or Cort $10 \mathrm{mg} / \mathrm{kg}$ ( $p=0.36$ and 0.33 , respectively) and no differences between Cort $3 \mathrm{mg} / \mathrm{kg}$ versus Cort $10 \mathrm{mg} / \mathrm{kg}(p=0.99)$. When freezing in the Cort groups at $48 \mathrm{~h}$ in $\boldsymbol{a}$ (retrieval block by Cort) was compared with that of Cort groups at $72 \mathrm{~h}$ in $\boldsymbol{b}$ (memory after retrieval block by Cort), there was no significant difference between Cort groups with retrieval blocked $(\boldsymbol{a})$ and Cort groups after retrieval blockade $(\boldsymbol{b})$ ( $p=0.26$ and 0.23 for 3 $\mathrm{mg} / \mathrm{kg}$ and $10 \mathrm{mg} / \mathrm{kg}$, respectively).

indicated a block of retrieval and Figure $4 b$ indicated no subsequent difference between controls and Cort groups, we conclude that corticosterone blocks retrieval without affecting subsequent memory expression. Although there was clearly a difference between retrieval in the presence of Cort (Fig. 4a) and no difference in subsequent retrieval (Fig. $4 b$ ), there was not a significant difference in this experiment between freezing levels in the Cort groups in Figure 4, $a$ and $b$. Because of this discrepancy, we repeated this experiment with $10 \mathrm{mg} / \mathrm{kg}$ corticosterone and found the same result of a significant block of retrieval and no significant impairment in subsequent memory (Student's $t$ test, $p<$ 0.05 for retrieval and $p=0.63$ for subsequent memory expression). In this additional experiment, there was a significant difference between $10 \mathrm{mg} / \mathrm{kg}$ Cort during retrieval ( $48 \mathrm{~h}$ after training) and the postretrieval memory expression ( $72 \mathrm{~h}$ after training; $p=0.01 ; n=6$ ) (data not shown). Thus, under our particular experimental conditions, blocking a single contextual memory retrieval does not have a significant effect on subsequent expression of the memory. It seems that glucocorticoids must be administered after successful reactivation of the fear memory to impair subsequent recall after a single reactivation trial, although a trend toward reduced subsequent memory was observed. It is possible, however, that with a different experimental protocol, one might find a significant one-trial effect of pre-reactivation corticosterone on subsequent memory.
The effects of glucocorticoids on subsequent fear memory recall and on acute retrieval are not caused by nonspecific alterations in behavior but are rather a selective effect of glucocorticoids on these fear memory processes themselves. Acute administration of $3.0 \mathrm{mg} / \mathrm{kg}$ corticosterone, a dose that can impair fear memory retrieval or subsequent memory, depending on the timing of application, does not alter open-field locomotor activity or open field measures of anxiety such as time spent in the center (supplemental Fig. 1, available at www.jneurosci.org as supplemental material). The same dose of corticosterone also has no effect on anxiety measures in the elevated plus maze (supplemental Fig. 2, available at www.jneurosci.org as supplemental material), gross motor coordination in the accelerating rotarod (supplemental Fig. 3, available at www.jneurosci.org as supplemental material), or footshock sensitivity (supplemental Fig. 4, available at www.jneurosci.org as supplemental material). These negative findings in mice are interesting in light of previous findings that glucocorticoids increase anxiety/arousal in human subjects (Abercrombie et al., 2005). It may be that our tests of anxiety in rodents are not as sensitive as measures in human studies. These control data further support a selective effect of glucocorticoids on fear memory retrieval processes.

Although the effects of glucocorticoids given before a single reactivation trial do not significantly affect subsequent memory recall, we did observe a trend toward a decrease in subsequent memory (Fig. 4b). Based on this result, we hypothesized that reactivation of fear memory during glucocorticoid inhibition of retrieval might enhance the extinction process after multiple reactivations. Thus, we tested the effects of repeated corticosterone block of retrieval on extinction. Three days of repeated corticosterone administration before reactivation (context exposure) trials led to decreased fear memory expression $(p<0.05)$ (Fig. $5 a)$. When the underlying memory trace was examined $1 \mathrm{~d}$ later in the absence of corticosterone, inhibition of fear expression remained enhanced ( $p<0.01$ ) (Fig. 5a). Thus, glucocorticoids may affect subsequent recall of an established memory if given after a single reactivation and may also augment extinction if given before multiple reactivation trials. In this case, the inhibition of fear expression could be a result of a direct effect of corticosterone to enhance consolidation of extinction or resulting from blockade of fear memory retrieval during extinction. Repeated trials of post-reactivation corticosterone led to a similar effect $(p<0.01)$ (Fig. $5 b)$, indicating a likely effect on consolidation of extinction memory, although a separate effect of decreasing retrieval on extinction cannot be excluded. Interestingly, multiple trials of post-reactivation corticosterone prolonged the extinction effect. Although single-trial post-reactivation corticosterone effects showed spontaneous recovery of memory by $72 \mathrm{~h}$ (Fig. 1c), multiple-trial post-reactivation corticosterone effects lasted at least $72 \mathrm{~h}(p<0.001)$ (Fig. $5 b)$. Both preretrieval and post-retrieval corticosterone effects with multiple trials were dependent on reactivation of the memory and were not simply an effect of repeated corticosterone administration $(p=0.97)$ (Fig. $5 c)$.

\section{Discussion}

These findings demonstrate that administration of the endogenous stress hormone, corticosterone, after a single memory reactivation can impair subsequent recall of an established contextual fear memory. Previous studies have implicated glucocorticoids in modulation of extinction of other types of fear memory (Bohus and Lissak, 1968; Micheau et al., 1982; Barrett and GonzalezLima, 2004; Moreira et al., 2004; Yang et al., 2006), primarily 
using cue-elicited fear memory. The facilitation of contextual fear memory extinction may have particular relevance for acquired anxiety disorders. Interestingly, the effect of glucocorticoids on subsequent recall is the opposite of its effect on memory consolidation. Such a post-reactivation effect of a drug may be interpreted as either inhibition of reconsolidation or as augmentation of extinction learning.

Post-reactivation corticosterone may act by inhibiting reconsolidation of the reactivated memory. Memory consolidation and reactivation-induced memory "lability" appear to be dependent on some overlapping molecular mechanisms such as NMDA receptor activation, $\beta$-adrenergic receptor activation, and cAMP response element-binding protein activation, whereas some manipulations can affect one process and not the other (Bourtchuladze et al., 1994; Przybyslawski and Sara, 1997; Przybyslawski et al., 1999; Cahill et al., 2000; Sara, 2000; Kida et al., 2002; McGaugh, 2002; McGaugh and Roozendaal, 2002; Debiec and Ledoux, 2004; Lee et al., 2004). Certainly, the initial effect of corticosterone is similar in magnitude to the effect of anisomycin, a drug which empirically defines reconsolidation effects in rodents (Nader et al., 2000a,b; Sara, 2000; Debiec et al., 2002). Also, the effect of corticosterone, like that of anisomycin, is only present after reactivation of the memory and not in the absence of reactivation. Indeed, blocking retrieval of the memory seems to decrease the effect of corticosterone on subsequent memory. However, the effect of single-trial post-reactivation corticosterone is transient. In theory, a drug that decreases the reconsolidation of a memory is predicted to have a lasting effect. In many reports, the effect of anisomycin on reconsolidation is sustained (Lattal and Abel, 2001; Debiec et al., 2002), although other studies demonstrate spontaneous recovery of memory after various post-retrieval manipulations, including anisomycin (Miller and Springer, 1974; Mactutus et al., 1979; Judge and Quartermain, 1982; Anokhin et al., 2002; Lattal and Abel, 2004). Although some have suggested that preservation of the underlying memory after postretrieval manipulations might be incorporated into theories of reconsolidation (Lattal and Abel, 2004), corticosterone does not permanently impair recall performance.

Another interpretation is that corticosterone is augmenting consolidation of contextual fear memory extinction, an effect observed in studies of other forms of memory (Bohus and Lissak, 1968; Micheau et al., 1982; Barrett and Gonzalez-Lima, 2004; Moreira et al., 2004; Yang et al., 2006). One-trial extinction of contextual fear conditioning would be exceptional and does not occur under our control conditions (Fig. 1a, "vehicle"). It is possible, however, that corticosterone is acting to augment consolidation of extinction memory such that one trial is sufficient to induce weak extinction that is only transiently expressed. One property of extinction is that the original memory can show spontaneous recovery (Bouton, 1993; Myers and Davis, 2002), similar to the transient effect of post-reactivation corticosterone. The need for reactivation of memory for the effect is also consistent with a need for reactivation of memory in the extinction process. Finally, the extinction process can be overcome by a subthreshold reminder shock, whereas a deficit in reconsolida-

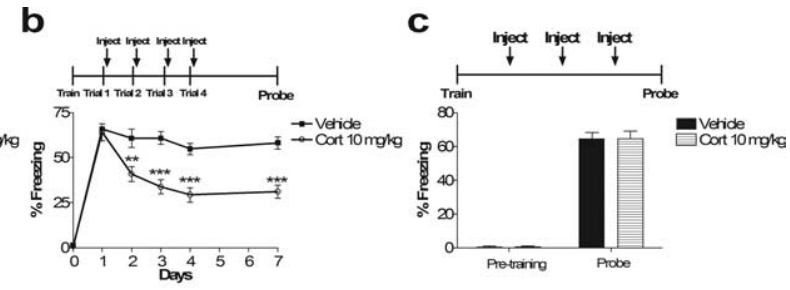

b

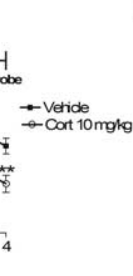

Figure 5. Corticosterone augments multiple-trial extinction. $\boldsymbol{a}$, Corticosterone blockade of retrieval augments extinction. This effect is dependent on multiple reactivation trials (compare with Fig. 4b). Repeated injection of corticosterone 30 min before extinction trials for $3 \mathrm{~d}$ impairs both retrieval acutely and subsequent memory recall tested $24 \mathrm{~h}$ after the last extinction trial in the absence of corticosterone. ANOVA with repeated measures on days $1-3$ indicates a main effect of $\operatorname{drug}\left(F_{(1,18)}=6.29 ; p<0.05\right)$. Student's $t$ test of day 4 indicates $p<0.01$. Individual $t$ tests for days 1,2 , and 3 indicate $p=0.14, p<0.05$, and $p<0.05$, respectively. $n=10$ in all groups. $\boldsymbol{b}$, Multiple trials of post-reactivation corticosterone further augment extinction measured $24 \mathrm{~h}$

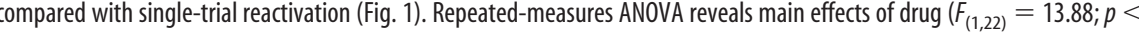
extinction with multiple trials requires memory reactivation. Multiple daily injections of corticosterone in the absence of memory uent memory recall. Student's $t$ test of probe: $p=0.97 ; n=12$ in all groups.

tion cannot. The post-reactivation glucocorticoid effect on contextual fear memory is reversed by reminder shock in our hands, unlike that of anisomycin. Thus, augmentation of single-trial contextual fear memory extinction is the more likely mechanism for post-reactivation effects of corticosterone on subsequent memory.

Augmentation of contextual fear extinction by glucocorticoids is consistent with several previous findings in the literature. For example, corticosterone is known to increase consolidation of other forms of memory (McGaugh and Roozendaal, 2002; Roozendaal, 2002). Similarly, previous reports suggest that prereactivation and post-reactivation glucocorticoids may play a role in the treatment of PTSD and phobia (Aerni et al., 2004; Soravia et al., 2006). Furthermore, extinction may be modulated by glucocorticoids in other forms of memory (Bohus and Lissak, 1968; Micheau et al., 1982; Barrett and Gonzalez-Lima, 2004; Moreira et al., 2004; Yang et al., 2006)

Similar to previous findings (de Quervain et al., 1998; Roozendaal et al., 2004), we demonstrated that glucocorticoids block fear memory retrieval in a contextual fear-conditioning paradigm. We extended this finding by demonstrating that glucocorticoids given before a single-trial retrieval do not significantly affect the long-term stability of the underlying memory trace, nor do they affect control behaviors that might interfere with measures of memory retrieval. Furthermore, we confirmed observations by de Quervain et al. (1998) indicating that increased glucocorticoids in the absence of reactivation do not affect subsequent recall when glucocorticoid levels had returned to baseline (de Quervain et al., 1998). Thus, successful retrieval of fear memory is necessary for glucocorticoid effects on subsequent memory recall after a single-trial reactivation. Similar effects of glucocorticoids on memory retrieval have been observed in humans (de Quervain et al., 2000). Additionally, we have significantly extended previous findings that pre-reactivation or postreactivation glucocorticoids can decrease repeated-trial, cued fear memories (Yang et al., 2006) by examining the time course, spontaneous recovery, comparison to anisomycin, and sensitivity to reminder shock to distinguish extinction and retrieval from reconsolidation effects on contextual fear memories.

The glucocorticoid effects are present whether the glucocorti- 
coid is administered before or after each extinction trial (Fig. 5). Administration of glucocorticoids after a single reactivation trial likely augments consolidation of extinction. Administration of glucocorticoids $30 \mathrm{~min}$ before multiple reactivation trials can also enhance extinction, either by augmenting extinction consolidation or as a result of decreasing contextual fear memory retrieval.

It is tempting to speculate about the role of glucocorticoids in susceptibility to and maintenance of learned anxiety disorders such as posttraumatic stress disorder. Patients with PTSD have been shown to have lower circulating levels of corticosterone and altered hypothalamic-pituitary axis activity (Yehuda, 2002). Blunted corticosterone responses might actually lead to persistent, pathologically strong, traumatic memories in affected individuals. Repeated reactivation of memories in unaffected individuals, followed by normal corticosterone surges, may serve to weaken their ability to recall traumatic memories over time. In contrast, a blunted corticosterone response may result in blunted extinction processes with pathologically persistent fear responses to contextual cues. The longer-lasting effect of multiple-trial postreactivation corticosterone is consistent with this possibility.

The clinical implications of pharmacologic interventions that decrease the strength of an established fear memory trace are clear. Glucocorticoids have been used in clinical trials to decrease symptoms of PTSD and phobia (Aerni et al., 2004; Soravia et al., 2006). Our data confirm that not only is the particular pharmacologic agent of importance, but that the reactivation of relevant memories, timing of administration relative to reactivation, and number of reactivation trials can have an impact on the desired outcome. The use of mice in the present study will allow directed investigation of the underlying receptor subtypes and mechanisms of the effect of glucocorticoid on established fear memories, affording the potential for more specific therapy in future trials that might allow us to avoid some side effects of a general treatment with glucocorticoids. In deference to ethical issues surrounding therapies targeted to emotional memories, it will be important in clinical trials to distinguish between suppression of the pathologically intense emotional valence of a traumatic memory versus the elimination of the declarative memory of said event.

In conclusion, glucocorticoids transiently decrease subsequent recall of an established fear memory after its reactivation, likely through augmentation of extinction in a single trial. Glucocorticoids have two effects on reactivated emotional memories. When administered before a single reactivation, memory retrieval is inhibited, whereas the stability of the underlying memory is unaffected. When drug administration follows memory reactivation, subsequent recall is dramatically reduced. Repeated administration may obviate the need for such precise timing. These studies provide a model for a therapeutic approach in the treatment of pathological emotional memories (Aerni et al., 2004; Schelling et al., 2004) and suggest future experiments designed to explore the specific molecular mechanisms of this effect.

\section{References}

Abel T, Lattal KM (2001) Molecular mechanisms of memory acquisition, consolidation and retrieval. Curr Opin Neurobiol 11:180-187.

Abercrombie HC, Kalin NH, Davidson RJ (2005) Acute cortisol elevations cause heightened arousal ratings of objectively nonarousing stimuli. Emotion 5:354-359.

Aerni A, Traber R, Hock C, Roozendaal B, Schelling G, Papassotiropoulos A, Nitsch RM, Schnyder U, de Quervain DJ (2004) Low-dose cortisol for symptoms of posttraumatic stress disorder. Am J Psychiatry 161:1488-1490.
Anokhin KV, Tiunova AA, Rose SP (2002) Reminder effects-reconsolidation or retrieval deficit? Pharmacological dissection with protein synthesis inhibitors following reminder for a passive-avoidance task in young chicks. Eur J Neurosci 15:1759-1765.

Barrett D, Gonzalez-Lima F (2004) Behavioral effects of metyrapone on pavlovian extinction. Neurosci Lett 371:91-96.

Bohus B, Lissak K (1968) Adrenocortical hormones and avoidance behaviour of rats. Int J Neuropharmacol 7:301-306.

Bourtchuladze R, Frenguelli B, Blendy J, Cioffi D, Schutz G, Silva AJ (1994) Deficient long-term memory in mice with a targeted mutation of the cAMP-responsive element-binding protein. Cell 79:59-68.

Bourtchouladze R, Abel T, Berman N, Gordon R, Lapidus K, Kandel ER (1998) Different training procedures recruit either one or two critical periods for contextual memory consolidation, each of which requires protein synthesis and PKA. Learn Mem 5:365-374.

Bouton ME (1993) Context, time, and memory retrieval in the interference paradigms of pavlovian learning. Psychol Bull 114:80-99.

Cahill L, Pham CA, Setlow B (2000) Impaired memory consolidation in rats produced with beta-adrenergic blockade. Neurobiol Learn Mem 74:259-266.

Davis HP, Squire LR (1984) Protein synthesis and memory: a review. Psychol Bull 96:518-559.

de Quervain DJ, Roozendaal B, McGaugh JL (1998) Stress and glucocorticoids impair retrieval of long-term spatial memory. Nature 394:787-790.

de Quervain DJ, Roozendaal B, Nitsch RM, McGaugh JL, Hock C (2000) Acute cortisone administration impairs retrieval of long-term declarative memory in humans. Nat Neurosci 3:313-314.

Debiec J, Ledoux JE (2004) Disruption of reconsolidation but not consolidation of auditory fear conditioning by noradrenergic blockade in the amygdala. Neuroscience 129:267-272.

Debiec J, LeDoux JE, Nader K (2002) Cellular and systems reconsolidation in the hippocampus. Neuron 36:527-538.

Dudai Y (2004) The neurobiology of consolidations, or, how stable is the engram? Annu Rev Psychol 55:51-86.

Flexner LB, Flexner JB, Stellar E (1965) Memory and cerebral protein synthesis in mice as affected by graded amounts of puromycin. Exp Neurol $13: 264-272$.

Hebda-Bauer EK, Watson SJ, Akil H (2004) CREB deficient mice show inhibition and low activity in novel environments without changes in stress reactivity. Eur J Neurosci 20:503-513.

Judge ME, Quartermain D (1982) Characteristics of retrograde amnesia following reactivation of memory in mice. Physiol Behav 28:585-590.

Kida S, Josselyn SA, de Ortiz SP, Kogan JH, Chevere I, Masushige S, Silva AJ (2002) CREB required for the stability of new and reactivated fear memories. Nat Neurosci 5:348-355.

Lattal KM, Abel T (2001) Different requirements for protein synthesis in acquisition and extinction of spatial preferences and context-evoked fear. J Neurosci 21:5773-5780.

Lattal KM, Abel T (2004) Behavioral impairments caused by injections of the protein synthesis inhibitor anisomycin after contextual retrieval reverse with time. Proc Natl Acad Sci USA 101:4667-4672.

Lee JL, Everitt BJ, Thomas KL (2004) Independent cellular processes for hippocampal memory consolidation and reconsolidation. Science 304:839-843

Mactutus CF, Riccio DC, Ferek JM (1979) Retrograde amnesia for old (reactivated) memory: some anomalous characteristics. Science 204:1319-1320.

McGaugh JL (2000) Memory-a century of consolidation. Science 287:248-251.

McGaugh JL (2002) Memory consolidation and the amygdala: a systems perspective. Trends Neurosci 25:456

McGaugh JL, Roozendaal B (2002) Role of adrenal stress hormones in forming lasting memories in the brain. Curr Opin Neurobiol 12:205-210.

Micheau J, Destrade C, Soumireu-Mourat B (1982) Posttrial injections of corticosterone in dorsal hippocampus of the BALB/c mouse facilitate extinction of appetitive operant conditioning in the Skinner box. C R Seances Acad Sci III 294:1109-1112.

Miller RR, Springer AD (1974) Implications of recovery from experimental amnesia. Psychol Rev 81:470-473.

Moreira PS, Pulman KG, Pottinger TG (2004) Extinction of a conditioned response in rainbow trout selected for high or low responsiveness to stress. Horm Behav 46:450-457. 
Myers KM, Davis M (2002) Behavioral and neural analysis of extinction. Neuron 36:567-584.

Nader K, Schafe GE, Le Doux JE (2000a) Fear memories require protein synthesis in the amygdala for reconsolidation after retrieval. Nature 406:722-726.

Nader K, Schafe GE, LeDoux JE (2000b) The labile nature of consolidation theory. Nat Rev Neurosci 1:216-219.

Pawlak R, Magarinos AM, Melchor J, McEwen B, Strickland S (2003) Tissue plasminogen activator in the amygdala is critical for stress-induced anxiety-like behavior. Nat Neurosci 6:168-174.

Pedreira ME, Maldonado H (2003) Protein synthesis subserves reconsolidation or extinction depending on reminder duration. Neuron 38:863-869.

Pitman RK, Sanders KM, Zusman RM, Healy AR, Cheema F, Lasko NB, Cahill L, Orr SP (2002) Pilot study of secondary prevention of posttraumatic stress disorder with propranolol. Biol Psychiatry 51:189-192.

Powell CM, Schoch S, Monteggia L, Barrot M, Matos MF, Feldmann N, Sudhof TC, Nestler EJ (2004) The presynaptic active zone protein RIMlalpha is critical for normal learning and memory. Neuron 42:143-153.

Przybyslawski J, Sara SJ (1997) Reconsolidation of memory after its reactivation. Behav Brain Res 84:241-246.

Przybyslawski J, Roullet P, Sara SJ (1999) Attenuation of emotional and nonemotional memories after their reactivation: role of $\beta$ adrenergic receptors. J Neurosci 19:6623-6628.

Roozendaal B (2002) Stress and memory: opposing effects of glucocorti- coids on memory consolidation and memory retrieval. Neurobiol Learn Mem 78:578-595.

Roozendaal B, de Quervain DJ, Schelling G, McGaugh JL (2004) A systemically administered beta-adrenoceptor antagonist blocks corticosteroneinduced impairment of contextual memory retrieval in rats. Neurobiol Learn Mem 81:150-154.

Sara SJ (2000) Retrieval and reconsolidation: toward a neurobiology of remembering. Learn Mem 7:73-84.

Schelling G, Roozendaal B, De Quervain DJ (2004) Can posttraumatic stress disorder be prevented with glucocorticoids? Ann NY Acad Sci 1032:158-166.

Schneider AM, Sherman W (1968) Amnesia: a function of the temporal relation of footshock to electroconvulsive shock. Science 159:219-221.

Soravia LM, Heinrichs M, Aerni A, Maroni C, Schelling G, Ehlert U, Roozendaal B, de Quervain DJ (2006) Glucocorticoids reduce phobic fear in humans. Proc Natl Acad Sci USA 103:5585-5590.

Suzuki A, Josselyn SA, Frankland PW, Masushige S, Silva AJ, Kida S (2004) Memory reconsolidation and extinction have distinct temporal and biochemical signatures. J Neurosci 24:4787-4795.

Vaiva G, Ducrocq F, Jezequel K, Averland B, Lestavel P, Brunet A, Marmar CR (2003) Immediate treatment with propranolol decreases posttraumatic stress disorder two months after trauma. Biol Psychiatry 54:947-949.

Yang YL, Chao PK, Lu KT (2006) Systemic and intra-amygdala administration of glucocorticoid agonist and antagonist modulate extinction of conditioned fear. Neuropsychopharmacology 31:912-924.

Yehuda R (2002) Current status of cortisol findings in post-traumatic stress disorder. Psychiatr Clin North Am 25:341-368, vii. 